\title{
Fetal exposure markers of dioxins and dioxin-like PCBs
}

\author{
Erik Lampa $^{1} \cdot$ Akifumi Eguchi $^{2} \cdot$ Emiko Todaka $^{2} \cdot$ Chisato Mori $^{2}$ \\ Received: 15 May 2017 / Accepted: 31 January 2018 / Published online: 15 February 2018 \\ (C) The Author(s) 2018. This article is an open access publication
}

\begin{abstract}
Fetal exposure to polychlorinated biphenyls (PCBs), polychlorinated-p-dibenzodioxins (PCDDs), and polychlorinated dibenzofurans (PCDFs) have been associated with a number of adverse health outcomes. Although the placenta acts as a barrier between the mother and the fetus, these contaminants transfer through the placenta exposing the fetus. Several studies have investigated placental transfer, but few have assessed the co-variation among these contaminants. Maternal blood, cord blood, and cord tissue were collected from 41 Japanese mother-infant pairs and analyzed for dioxin-like PCBs and PCDD/Fs. Hierarchical cluster analysis followed by principal component analysis were used to assess the co-variation. Two stable clusters of dioxin-like PCBs were found in maternal and cord blood. One cluster of low/medium chlorinated dioxin-like PCBs was present in all three matrices with $2,3^{\prime}, 4,4^{\prime}, 5-\mathrm{PeCB}(\# 118)$ and 3,3',4,4',5-PeCB(\#126) explaining the majority of the clusters' variances. Medium/high chlorinated dioxin-like PCBs clustered in maternal blood and cord blood but not in cord tissue. 2,3,4,4',5-PeCB(\#114) and 2,3,3',4,4',5,5'-HpCB(\#189) explained the majority of the clusters' variances. There was a substantial correlation between the sum of dioxin-like PCBs and total PCDD/F in all three matrices. The sum of the four suggested PCBs plus 3,3',4,4'-TeCB(\#77) correlated well with total PCDD/F in all three matrices. Apart from the dioxin-like PCBs, little co-variation existed among the studied contaminants. The five PCBs can be used as fetal exposure markers for dioxin and dioxin-like PCBs in maternal and cord blood respectively. In cord tissue, more higher chlorinated dioxin-like PCBs need to be measured as well.
\end{abstract}

Keywords PCB $\cdot$ Dioxin $\cdot$ Fetal exposure $\cdot$ Multivariate analysis

\section{Introduction}

Polychlorinated biphenyls (PCBs), polychlorinated$p$-dibenzodioxins (PCDDs), and polychlorinated

Responsible Editor: Philippe Garrigues

This study was supported by grants for Scientific Research (B): Grants-in-Aid for Scientific Research <KAKENHI (24310021)> from the Japanese Ministry of Education Culture, Sports, Science and Technology, and the Environment Research and Technology Development Fund (5-1305) from the Ministry of the Environment of Japan.

Electronic supplementary material The online version of this article (https://doi.org/10.1007/s11356-018-1447-y) contains supplementary material, which is available to authorized users.

Erik Lampa

erik.lampa@ucr.uu.se

1 UCR - Uppsala Clinical Research Center, Uppsala Science Park, Hubben, 75185 Uppsala, Sweden

2 Center for Preventive Medical Sciences, Chiba University, Chiba, Japan dibenzofurans (PCDFs) are widespread environmental contaminants that have been associated with numerous adverse health effects in humans such as increased cancer risk (Kogevinas 2001; Oakley et al. 1996), reproductive disorders (Crain et al. 2008), and nervous system damage (Grandjean and Landrigan 2006). Although the use and production of them is banned in large parts of the world, they continue to persist in the environment and accumulate in human adipose tissue. Of special concern is the exposure of a developing fetus because of potentially increased vulnerability during critical development stages. Epidemiological studies have linked maternal exposure to PCBs and PCDD/Fs to health outcomes such as growth restriction (Govarts et al. 2012), neurobehavioral deficits (Grandjean et al. 2001), and impaired immune response in the child (Svensson et al. 1994). Accumulated contaminants are passed from the mother to the fetus through the placenta and the umbilical cord. Although the placenta acts as a barrier protecting the growing fetus, PCBs and dioxins as groups easily pass the placenta (Lancz et al. 2014). However, PCBs and PCDD/Fs are mixtures of different congeners, each with their own physiochemical properties. Congeners with 
lower molecular weight are more likely to pass the placenta than congeners with higher molecular weight (Eguchi et al. 2015; Mori et al. 2014). While placental transfer has been investigated in several studies, few studies have investigated the co-variation of PCBs and dioxins. The aim of this study was to assess the degree of co-variation among dioxins and dioxin-like PCBs in maternal blood, cord blood, and cord tissue and to find suitable markers of exposure.

\section{Material and Methods}

\section{Data collection}

Maternal blood, umbilical cord blood, and cord tissue were collected from 41 mother-infant pairs at Chiba University Hospital and at various other obstetrics units in Japan during 2003 and 2004. Blood samples were stored at $-20^{\circ} \mathrm{C}$ until use. Umbilical cords were collected immediately after delivery and stored in acetone-washed glass bottles at $-20^{\circ} \mathrm{C}$ until use. Concentrations of seven PCDDs, 10 PCDFs and 12 dioxin-like PCBs were measured in all three matrices. TEQ-calculated values, using the WHO 2005 Toxic Equivalence Factors (TEF) (Van den Berg et al. 2006), were used in all statistical analyses. Further details on the data collection and chemical analyses can be found in Sakurai et al. (2004), Kawashiro et al. (2008), and Mori et al. (2014). The age distribution of the mothers is given in Table 1. The study was approved by the Congress of Medical Bioethics at Chiba University, and all samples were obtained after receipt of written informed consent.

\section{Statistical methods}

Hierarchical cluster analysis, which groups the contaminants into distinct clusters based on a measure of similarity between them, was used to quantify how the contaminants co-vary within each data set. Here, $1-|\rho|$, where $\rho$ is Spearman's rank correlation coefficient and |.| denotes the absolute value, was used as the dissimilarity measure. Cluster stability was evaluated using multistage multiscale bootstrap (Shimodiara 2005) in which the clustering in

Table 1 Age distribution of the 41 mothers participating in the study

\begin{tabular}{ll}
\hline Age group (years) & $N$ \\
\hline $20-24$ & 2 \\
$25-29$ & 11 \\
$30-34$ & 20 \\
35 and above & 8 \\
Total & 41 \\
\hline
\end{tabular}

repeated resamples from the data, with sampling fractions ranging from 0.5 to 1.4 , is compared to the observed clustering. The agreement between observed clustering and resampled clustering is called the bootstrap probability (BP) value, and $z$-values for the BP-values for each sampling fraction were calculated according to $z=\Phi^{-1}(\mathrm{BP})$ where $\Phi^{-1}(\cdot)$ is the inverse of the standard normal distribution function. For each cluster, a line is then fitted to the $z$ values by $z(\lambda)=\alpha \sqrt{\lambda}+\beta \sqrt{\lambda^{-1}}$ where $\lambda$ denotes the sampling fraction. Asymptotically unbiased probability values (AU $p$ values) were then calculated for each cluster by $\mathrm{AU}=\Phi(-\alpha+\beta)$. Stable clusters were defined as clusters with $\mathrm{AU} \geq 0.95$.

To assess whether a smaller subset of contaminants could explain the majority of the variability within each identified cluster, we performed a principal component analysis within each stable cluster containing more than two contaminants. The contaminants were first transformed to zero mean and unit variance by the maximum generalized variance (MGV) method (Harrell 2001). The MGV algorithm transforms the contaminants in an iterative fashion where each contaminant is represented using restricted cubic splines. In each step, canonical variate analysis is used to find optimal transformations so that each contaminant is most similar to predictions from the other contaminants. The process is repeated until the transformations converge. Each stable cluster was represented by the first principal component score. We then used a multiple linear regression model to predict the score, using restricted cubic splines with knots placed at the $10^{t h}, 50^{t h}$, and $90^{t h}$ percentiles of each contaminant's distribution for each constituent contaminant, and measured the decrease in the coefficient of determination, $R^{2}$, from stepwise deletions until $R^{2} \approx 0.95$. The contaminants left in the model were deemed suitable markers for that cluster.

Associations between $\Sigma \mathrm{PCB}_{\mathrm{R}}$ and $\Sigma \mathrm{PCDD} / \mathrm{F}$, where $\mathrm{PCB}_{\mathrm{R}}$ is the subset of dioxin-like PCBs needed to explain most of the variance in all dioxin-like PCBs, in maternal blood, cord blood and cord tissue were quantified using Spearman's rank correlation, $\rho$. Ninety-five percent confidence intervals for $\rho$ were calculated using the bootstrap with 10,000 replicates. We also estimated the correlation of the individual contaminants between the three matrices. Contaminant values below the limit of detection (LOD) were set to LOD/2. All analyses were done using R version 3.1.0 (R Core Team 2014) with the pvclust (Suzuki and Shimodaira 2011) and Hmisc (Harrell 2014) packages.

\section{Results}

Table 2 shows descriptive statistics for the data. Following Tsukimori et al. (2013), only compounds with $\geq 50 \%$ of 
Table 2 Descriptive statistics presented as median (IQR)

\begin{tabular}{|c|c|c|c|c|c|c|}
\hline \multirow[b]{2}{*}{ Contaminant } & \multicolumn{2}{|c|}{ Maternal blood } & \multicolumn{2}{|c|}{ Cord blood } & \multicolumn{2}{|c|}{ Cord tissue } \\
\hline & $N$ & Median (IQR) & $N$ & Median (IQR) & $N$ & Median (IQR) \\
\hline 2,3,7,8-TeCDD & 34 & $0.76(0.66-0.96)$ & 4 & $1.0(0.96-1.0)$ & 14 & $0.83(0.73-1.1)$ \\
\hline 1,2,3,7,8-PeCDD & 41 & $3.7(2.7-4.3)$ & 36 & $2.0(1.6-2.5)$ & 40 & $3.8(2.9-5.0)$ \\
\hline 1,2,3,4,7,8-HxCDD & 39 & $0.16(0.12-0.2)$ & 4 & $0.15(0.14-0.17)$ & 15 & $0.15(0.12-0.16)$ \\
\hline 1,2,3,6,7,8-HxCDD & 41 & $1.5(1.1-1.8)$ & 41 & $0.68(0.56-0.8)$ & 41 & $0.94(0.67-1.1)$ \\
\hline 1,2,3,7,8,9-HxCDD & 41 & $0.23(0.18-0.3)$ & 32 & $0.18(0.14-0.21)$ & 24 & $0.23(0.17-0.3)$ \\
\hline 1,2,3,4,6,7,8-HpCDD & 41 & $0.11(8.7 \mathrm{e}-2-0.16)$ & 41 & $4.6 \mathrm{e}-2(3.5 \mathrm{e}-2-6.8 \mathrm{e}-2)$ & 41 & $6.3 e-2(5.2 e-2-8.5 e-2)$ \\
\hline OCDD & 41 & $1.6 \mathrm{e}-2(1.2 \mathrm{e}-2-2.3 \mathrm{e}-2)$ & 41 & $4.1 \mathrm{e}-3(2.7 \mathrm{e}-3-5.8 \mathrm{e}-3)$ & 41 & $5 e-3(4.3 e-3-7.5 e-3)$ \\
\hline 2,3,7,8-TeCDF & 40 & $7.8 \mathrm{e}-2(6.6 \mathrm{e}-2-9.4 \mathrm{e}-2)$ & 24 & $7.3 e-2(6.4 e-2-8.9 e-2)$ & 15 & $7.8 \mathrm{e}-2(5.1 \mathrm{e}-2-0.11)$ \\
\hline $1,2,3,7,8-\mathrm{PeCDF}$ & 21 & $2.0 \mathrm{e}-2(1.7 \mathrm{e}-2-2.4 \mathrm{e}-2)$ & 5 & $2.8 \mathrm{e}-2(2.7 \mathrm{e}-2-3.2 \mathrm{e}-2)$ & 6 & $0.02(1.8 \mathrm{e}-2-2.7 \mathrm{e}-2)$ \\
\hline 2,3,4,7,8-PeCDF & 41 & $3.1(2.6-4.2)$ & 41 & $1.5(1.2-2)$ & 41 & $3.1(2.5-3.9)$ \\
\hline $1,2,3,4,7,8-\mathrm{HxCDF}$ & 41 & $0.25(0.21-0.33)$ & 39 & $0.14(0.11-0.18)$ & 40 & $0.27(0.22-0.31)$ \\
\hline $1,2,3,6,7,8-\mathrm{HxCDF}$ & 41 & $0.33(0.29-0.45)$ & 41 & $0.23(0.18-0.3)$ & 41 & $0.31(0.24-0.36)$ \\
\hline 1,2,3,7,8,9-HxCDF & 0 & - & 0 & - & 0 & - \\
\hline 2,3,4,6,7,8-HxCDF & 39 & $0.14(9.8 \mathrm{e}-2-0.18)$ & 16 & $0.11(0.1-0.12)$ & 29 & $0.12(8.9 \mathrm{e}-2-0.16)$ \\
\hline $1,2,3,4,6,7,8-\mathrm{HpCDF}$ & 41 & $2.3 \mathrm{e}-2(1.9 \mathrm{e}-2-3.4 \mathrm{e}-2)$ & 39 & $1.7 \mathrm{e}-2(1.4 \mathrm{e}-2-2.4 \mathrm{e}-2)$ & 39 & $2.4 \mathrm{e}-2(1.8 \mathrm{e}-2-2.8 \mathrm{e}-2)$ \\
\hline $1,2,3,4,7,8,9-\mathrm{HpCDF}$ & 0 & - & 0 & - & 0 & - \\
\hline OCDF & 3 & $1.4 \mathrm{e}-4(1.3 \mathrm{e}-4-1.4 \mathrm{e}-4)$ & 0 & - & 0 & - \\
\hline$\sum P C D D / F$ & & $10(8.2-13)$ & & $4.8(3.5-5.1)$ & & $9.6(7.0-12)$ \\
\hline 3,3',4,4'-TeCB(\#77) & 41 & $5.3 e-4(4.2 e-4-6.6 e-4)$ & 40 & $3.8 \mathrm{e}-4(3.1 \mathrm{e}-4-5.2 \mathrm{e}-4)$ & 40 & $3.8 \mathrm{e}-4(3.1 \mathrm{e}-4-5.3 \mathrm{e}-4)$ \\
\hline 3,4,4',5-ТеCB(\#81) & 41 & $1.1 \mathrm{e}-4(8.5 \mathrm{e}-5-1.6 \mathrm{e}-4)$ & 18 & $9.2 \mathrm{e}-5(7.6 \mathrm{e}-5-1.1 \mathrm{e}-4)$ & 33 & $1.3 e-4(9.4 e-5-1.7 e-4)$ \\
\hline 2,3,3',4,4'-PeCB(\#105) & 41 & $0.1(7.1 \mathrm{e}-2-0.15)$ & 41 & $4.9 \mathrm{e}-2(3.1 \mathrm{e}-2-6.8 \mathrm{e}-2)$ & 41 & $0.075(0.06-0.11)$ \\
\hline 2,3,4,4',5-PeCB(\#114) & 41 & $0.12(9.5 e-2-0.2)$ & 41 & $5.8 \mathrm{e}-2(4.0 \mathrm{e}-2-9.0 \mathrm{e}-2)$ & 41 & $9.2 \mathrm{e}-2(7.9 \mathrm{e}-2-0.13)$ \\
\hline 2,3',4,4',5-PeCB(\#118) & 41 & $0.48(0.31-0.64)$ & 41 & $0.21(0.14-0.33)$ & 41 & $0.35(0.24-0.44)$ \\
\hline 2',3,4,4',5-PeCB(\#123) & 41 & $6.9 e-3(5.2 e-3-9.3 e-3)$ & 41 & $3.4 \mathrm{e}-3(2.7 \mathrm{e}-3-5.8 \mathrm{e}-3)$ & 41 & $5.4 \mathrm{e}-3(3.8 \mathrm{e}-3-7.2 \mathrm{e}-3)$ \\
\hline 3,3',4,4',5-PeCB(\#126) & 41 & $2.5(1.8-3.3)$ & 41 & $1(0.76-1.5)$ & 41 & $1.7(1.3-2.3)$ \\
\hline 2,3,3',4,4',5-HxCB(\#156) & 41 & $0.81(0.58-1.2)$ & 41 & $0.27(0.2-0.44)$ & 41 & $0.46(0.39-0.62)$ \\
\hline $2,3,3^{\prime}, 4,4^{\prime}, 5^{\prime}-\mathrm{HxCB}(\# 157)$ & 41 & $0.2(0.15-0.3)$ & 41 & $0.08(5.9 \mathrm{e}-2-0.13)$ & 41 & $0.12(0.10-0.17)$ \\
\hline $2,3^{\prime}, 4,4^{\prime}, 5,5^{\prime}-\mathrm{HxCB}(\# 167)$ & 41 & $6 e-3(4.5 e-3-8.2 e-3)$ & 41 & $2.3 e-3(1.8 e-3-3.5 e-3)$ & 41 & $3.6 e-3(2.6 e-3-4.7 e-3)$ \\
\hline 3,3',4,4',5,5'-НxСВ(\#169) & 41 & $0.22(0.18-0.29)$ & 41 & $7.6 e-2(5.8 \mathrm{e}-2-0.10)$ & 41 & $0.12(9.8 \mathrm{e}-2-0.15)$ \\
\hline $\left.2,3,3^{\prime}, 4,4^{\prime}, 5,5^{\prime}-\mathrm{HpCB}^{\prime} \# 189\right)$ & 41 & $1.8 \mathrm{e}-2(1.4 \mathrm{e}-2-2.4 \mathrm{e}-2)$ & 41 & $5.1 e-3(4.0 e-3-7.6 e-3)$ & 41 & $8.1 \mathrm{e}-3(6.6 \mathrm{e}-3-1.0 \mathrm{e}-2)$ \\
\hline$\sum P C B$ & & $4.6(3.3-6.0)$ & & $1.8(1.2-2.5)$ & & $3.0(2.2-3.7)$ \\
\hline$\sum P C D D / F$ and $P C B$ & & $15(12-19)$ & & $6.8(4.6-8.1)$ & & $13(9.6-16)$ \\
\hline
\end{tabular}

$N$ is the number of observations above the LOD. $x$ e $\pm y$ means $x \cdot 10^{ \pm y}$. All units are $\mathrm{pg}$-TEQ/g-fat

the samples above the LOD in all three matrices were considered for further statistical analysis.

Figure 1 shows the correlation coefficients for the dioxinlike PCBs and PCDD/Fs between all three matrices. Correlations between the dioxin-like $\mathrm{PCBs}$ in the different matrices were generally high with the exception of 3,3',4,4'TeCB(\#77). The PCDD/Fs correlated well between maternal and cord blood, but the correlation dropped somewhat between the other matrices.

Dendrograms from the hierarchical cluster analyses are shown in Figs. 2, 3, and 4. The $y$-axis in each figure represents the dissimilarity between the contaminants, with higher values reflecting less correlated contaminants. Stable clusters as judged by the bootstrap procedure are enclosed in dashed boxes.

\section{Stable clusters}

One stable cluster consisting of the low/medium chlorinated PCBs 2,3,3',4,4'-PeCB(\#105), 2,3',4,4',5-PeCB(\#118), 2',3,4,4',5-PeCB(\#123), and 3,3',4,4',5-PeCB(\#126) was present in all matrices. In addition, a stable cluster consisting of the medium/high chlorinated PCBs 2,3,3',4,4',5-НxСB(\#156), 2,3,3',4,4',5' -НxСB(\#157), 
Fig. 1 Spearman's rank correlation between individual $\mathrm{PCBs}$ and $\mathrm{PCDD} / \mathrm{Fs}$ in all three matrices

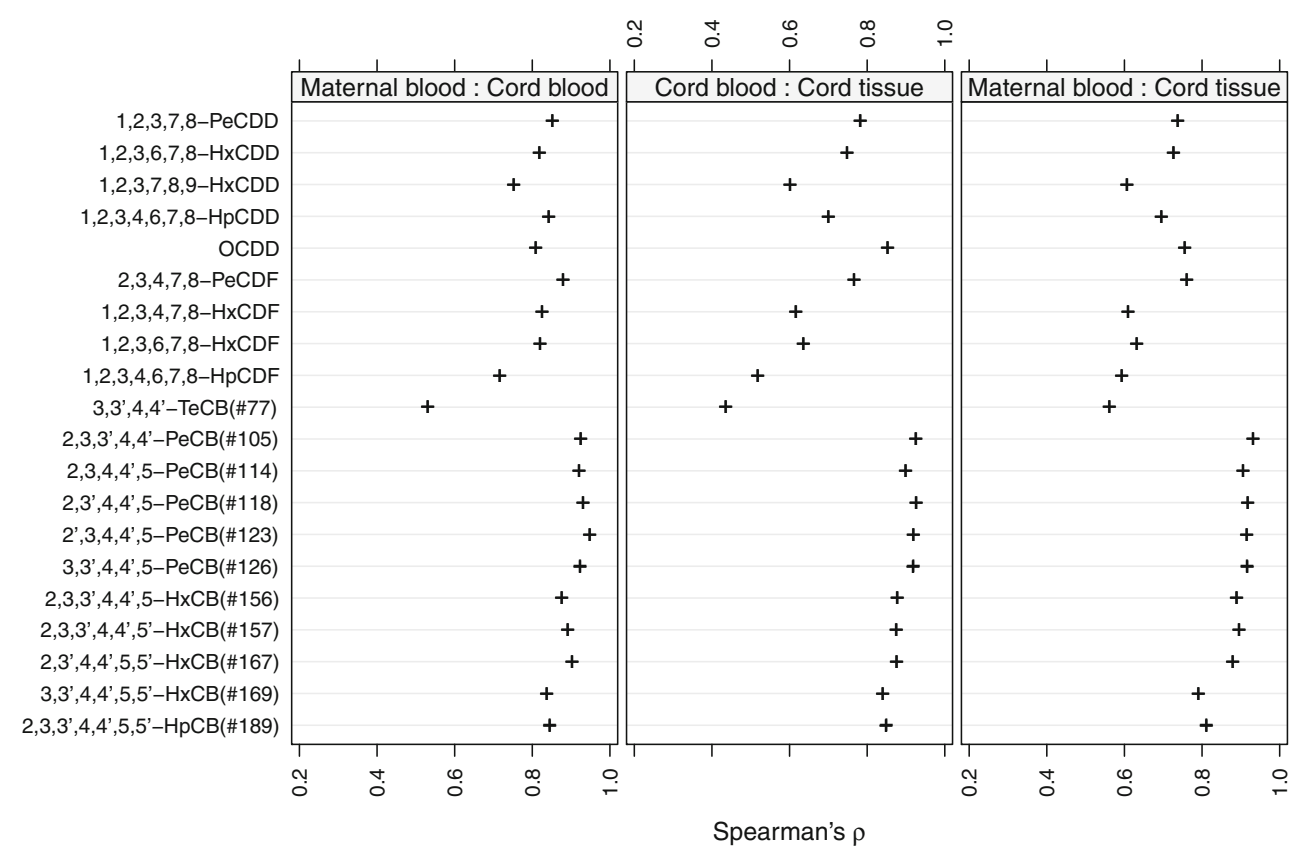

$2,3^{\prime}, 4,4^{\prime}, 5,5^{\prime}-\mathrm{HxCB}(\# 167)$,

$3,3^{\prime}, 4,4^{\prime}, 5,5^{\prime}-\mathrm{HxCB}(\# 169)$, $2,3,3^{\prime}, 4,4^{\prime}, 5,5^{\prime}-\mathrm{HpCB}(\# 189)$ as well as $2,3,4,4^{\prime}, 5-$ $\mathrm{PeCB}(\# 114)$ was found in maternal blood and cord blood. The cluster could also be seen in cord tissue; although, only a small sub-cluster consisting of 2,3,3',4,4',5-HxCB(\#156) and $2,3,3^{\prime}, 4,4^{\prime}, 5^{\prime}-\mathrm{HxCB}(\# 157)$ was deemed stable. Although 3,3',4,4'-TeCB(\#77) seemed to cluster with the other dioxin-like PCBs, it was not part of any stable cluster. No cluster with more than two constituent PCDD/Fs was seen in any of the matrices; although, a small cluster consisting of $1,2,3,4,7,8-\mathrm{HxCDF}$ and $1,2,3,6,7,8-\mathrm{HxCDF}$ was

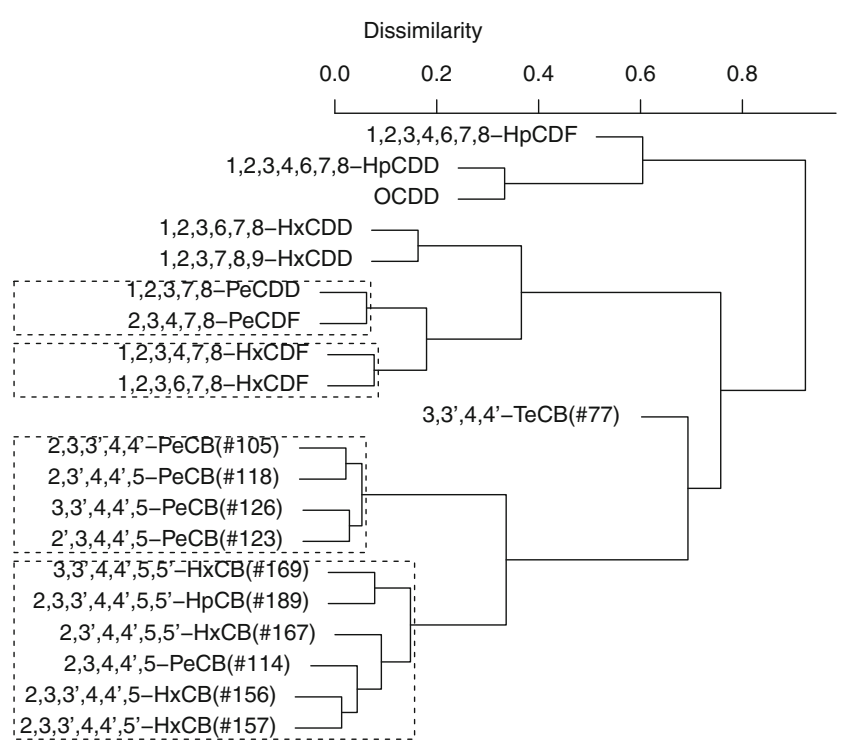

Fig. 2 Dendrogram showing the results of the cluster analysis applied in the maternal blood data. Stable clusters are enclosed in dashed boxes deemed stable in all three matrices. Both 1,2,3,7,8-PeCDD and 2,3,4,7,8-PeCDF clustered in maternal blood and cord blood.

\section{Suitable markers}

Table 3 shows the percent variance explained by the first principal component as well as $R^{2}$ from the regression models and the constituent contaminants. Generally, the first principal component explained a large amount of the variance in each cluster suggesting strong correlations among the constituent contaminants. For the

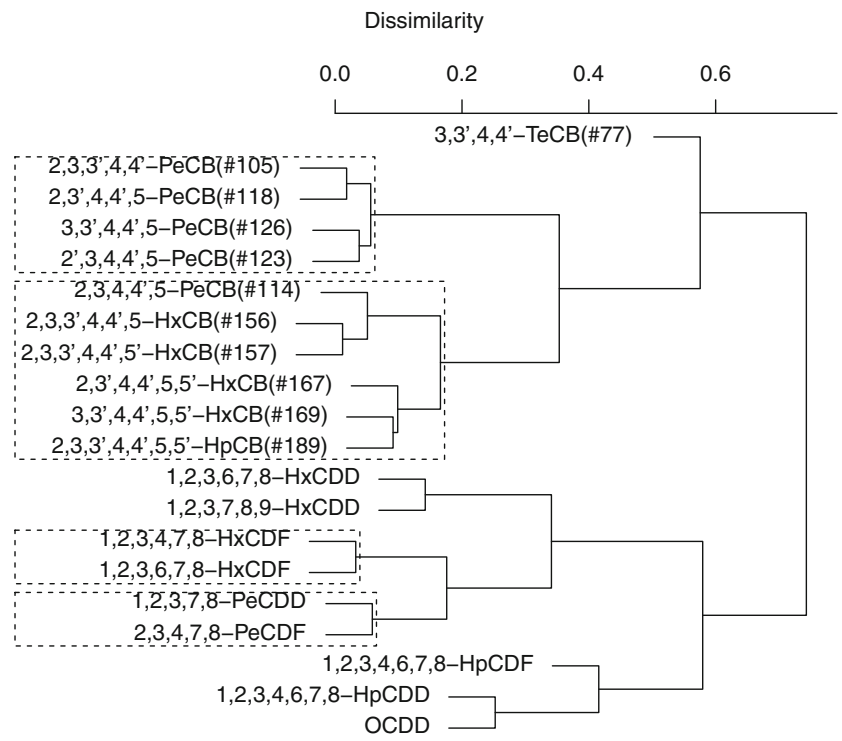

Fig. 3 Dendrogram showing the results of the cluster analysis applied in the cord blood data. Stable clusters are enclosed in dashed boxes 


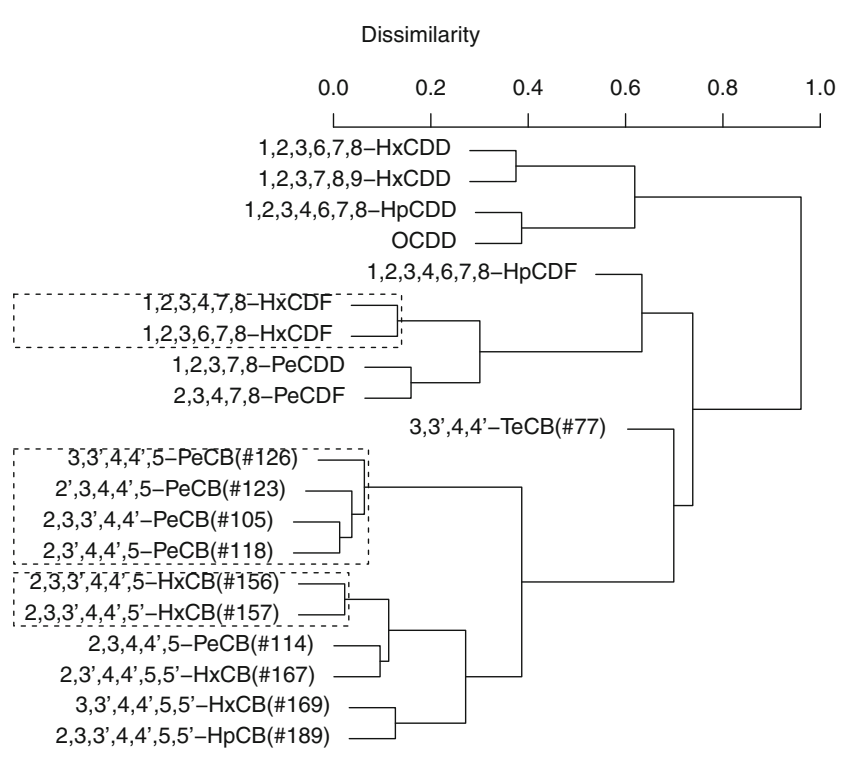

Fig. 4 Dendrogram showing the results of the cluster analysis applied in the cord tissue data. Stable clusters are enclosed in dashed boxes

low/medium chlorinated cluster, 2,3',4,4',5-PeCB(\#118) and 3,3',4,4',5-PeCB(\#126) could be seen as suitable markers in all three matrices. For the medium/high chlorinated cluster, 2,3,4,4',5-PeCB(\#114) and 2,3,3',4,4',5,5'$\mathrm{HpCB}(\# 189)$ could be suitable markers in maternal blood and cord blood.

\section{Relationship between $\Sigma P C B_{R}$ and $\Sigma P C D D / F$}

The relationships between $\Sigma \mathrm{PCB}_{\mathrm{R}}$ and $\Sigma \mathrm{PCDD} / \mathrm{F}$ in the three matrices can be seen in Fig. 5 and Table 4. The medium/high chlorinated PCBs 2,3,4,4',5-PeCB(\#114) and $2,3,3^{\prime}, 4,4^{\prime}, 5,5^{\prime}-\mathrm{HpCB}(\# 189)$ are part of $\mathrm{PCB}_{\mathrm{R}}$ in cord tissue despite the lack of a larger stable medium/high chlorinated cluster. Figure 5 contains an extra panel for cord tissue. In this panel, $\mathrm{PCB}_{\mathrm{R}}$ consists of 3,3',4,4'- $\mathrm{TeCB}(\# 77)$, $2,3^{\prime}, 4,4^{\prime}, 5-\mathrm{PeCB}(\# 118)$, and $3,3^{\prime}, 4,4^{\prime}, 5-\mathrm{PeCB}(\# 126)$ as well as all the dioxin-like PCBs in the medium/high chlorinated cluster. Table 4 shows the values of Spearman's $\rho$ and the $95 \%$ nonparametric bootstrap confidence intervals. $\Sigma \mathrm{PCB}_{\mathrm{R}}$ and $\Sigma \mathrm{PCDD} / \mathrm{F}$ were positively correlated in all three matrices with $\rho$ being highest in maternal blood followed by cord blood and cord tissue; although, the differences were small. The correlation between $\Sigma P C B_{R}$ and $\Sigma \mathrm{PCDD} / \mathrm{F}$ in cord tissue, when additional higher chlorinated dioxin-like PCBs were added to the sum of dioxin-like PCBs, was higher than the correlation when the additional dioxin-like PCBs were not added to the sum.

\section{Discussion}

This study has investigated the co-variation among PCDD/Fs and dioxin-like PCBs in three different matrices: maternal blood, umbilical cord blood, and umbilical cord tissue. We observed one stable cluster containing four PentaCBs in all three matrices (Figs. 2, 3, and 4) suggesting that these PCBs transfer through the placenta and accumulate in the cord tissue in a similar manner. Based on our results, measuring 3,3',4,4',5-PeCB(\#126) in addition to $2,3^{\prime}, 4,4^{\prime}, 5-\mathrm{PeCB}(\# 118)$ would be enough to get a good picture of fetal exposure to these PCBs. Furthermore, $3,3^{\prime}, 4,4^{\prime}, 5-\mathrm{PeCB}(\# 126)$ has the strongest toxicity among the co-planar PCBs and can, from a toxicity viewpoint, be used as a marker PCB. Since the correlations between the PCBs in different matrices were high (see Fig. 1), a sample from maternal blood could be used as a proxy for fetal exposure to dioxin-like PCBs and PCDD/Fs. For a biomonitoring study however, it is necessary to measure the contaminants in umbilical cord tissue as levels vary between the matrices (Fukata et al. 2005). Samples taken in maternal blood and cord blood also represent exposure levels in mothers while samples taken in cord tissue represent the cumulative exposure during the gestation period.
Table 3 Explained variance of the first principal component $\left(R_{\mathrm{PC} 1}^{2}\right), R^{2}$ and constituent contaminants for a model predicting the first principal component

\begin{tabular}{|c|c|c|c|c|}
\hline Matrix & Cluster & $R_{\mathrm{PC} 1}^{2}$ & $R^{2}$ & $\mathrm{PCB}_{\mathrm{R}}$ \\
\hline \multirow[t]{4}{*}{ Maternal blood } & \multirow[t]{2}{*}{ Low/medium chlorinated } & \multirow[t]{2}{*}{0.97} & \multirow[t]{2}{*}{1.00} & $2,3^{\prime}, 4,4^{\prime}, 5-\mathrm{PeCB}(\# 118)$ \\
\hline & & & & $3,3^{\prime}, 4,4^{\prime}, 5-\mathrm{PeCB}(\# 126)$ \\
\hline & \multirow[t]{2}{*}{ Medium/high chlorinated } & \multirow[t]{2}{*}{0.94} & \multirow[t]{2}{*}{0.99} & 2,3,4,4',5-PeCB(\#114) \\
\hline & & & & $2,3,3^{\prime}, 4,4^{\prime}, 5,5^{\prime}-\mathrm{HpCB}(\# 189)$ \\
\hline \multirow[t]{4}{*}{ Cord blood } & \multirow[t]{2}{*}{ Low/medium chlorinated } & \multirow[t]{2}{*}{0.94} & \multirow[t]{2}{*}{1.00} & 2,3',4,4',5-PeCB(\#118) \\
\hline & & & & 3,3',4,4',5-PeCB(\#126) \\
\hline & \multirow[t]{2}{*}{ Medium/high chlorinated } & \multirow[t]{2}{*}{0.97} & \multirow[t]{2}{*}{0.99} & 2,3,4,4’,5-PeCB(\#114) \\
\hline & & & & $2,3,3^{\prime}, 4,4^{\prime}, 5,5^{\prime}-\mathrm{HpCB}(\# 189)$ \\
\hline \multirow[t]{2}{*}{ Cord tissue } & \multirow[t]{2}{*}{ Low/medium chlorinated } & \multirow[t]{2}{*}{0.96} & \multirow[t]{2}{*}{0.99} & $2,3^{\prime}, 4,4^{\prime}, 5-\mathrm{PeCB}(\# 118)$ \\
\hline & & & & 3,3',4,4',5-PeCB(\#126) \\
\hline
\end{tabular}



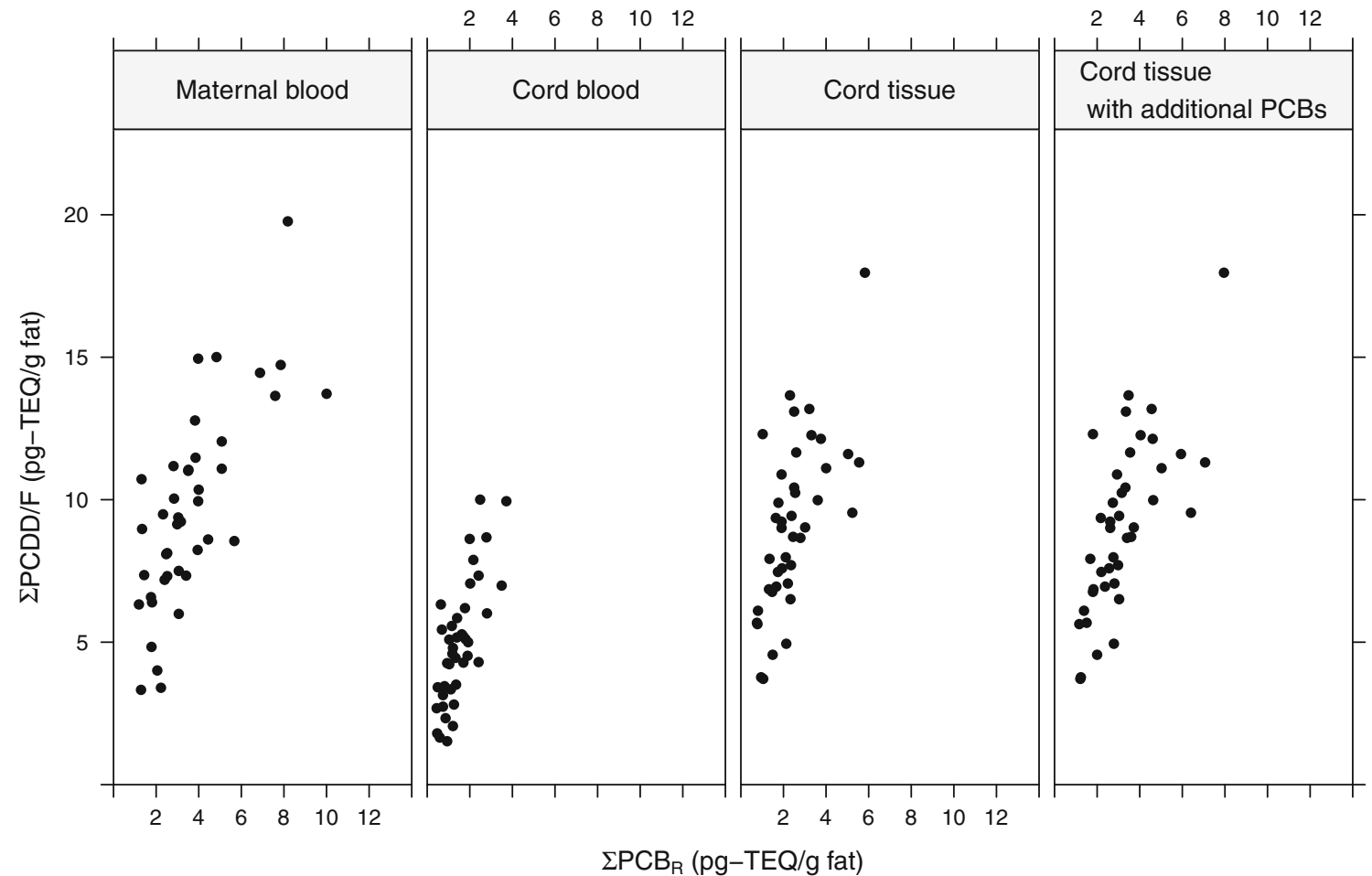

Fig. 5 Associations between total $\mathrm{PCDD} / \mathrm{F}$ and $\mathrm{PCB}_{\mathrm{R}}$ in the three matrices. The rightmost panel includes additional higher chlorinated dioxin-like PCBs in the sum

Another PCB cluster consisting mainly of HexaCBs, and one PentaCB, was observed in maternal blood and cord blood but not in cord tissue. Placental transfer is mainly determined by the molecular weight, with lighter compounds transferring more easily than heavier ones (Eguchi et al. 2015; Lancz et al. 2014). Although higher chlorinated PCBs are heavier than lower chlorinated ones, the weight difference is not enough to dissolve the cluster in cord blood. One reason for the lack of the highly chlorinated PCB cluster in cord tissue could be the lower levels of highly chlorinated PCBs in cord tissue. Lower levels, close to the LOD, have a high relative uncertainty, and although a rank-based measure was used in the clustering, it is possible that this uncertainty in measured levels has contributed to the uncertainty in the cluster. The two PCBs present in the small stable cluster in cord tissue are present in higher levels than the other PCBs included in the corresponding cluster in maternal blood or cord blood. The human body metabolizes PCBs differently depending on the degree of chlorination, with lower chlorinated PCBs generally being metabolized quicker than higher chlorinated PCBs (Grimm et al. 2015). This difference in metabolism could also explain the presence of a cluster of lower/medium chlorinated PCBs in cord tissue.

Clusters similar to what we observed in maternal blood were observed in data from the National Health and
Nutrition Survey (NHANES) and in an elderly population in Sweden (Lampa et al. 2012) where the degree of chlorination in part explained the clustering. It is obvious from our results that the degree of chlorination is a major determinant of the clustering in our data; although, the PentaCBs did not cluster together with 2,3,4,4',5$\operatorname{PeCB}(\# 114)$ which appeared in the medium/higher chlorinated cluster and especially clustered with $2,3,3^{\prime}, 4,4^{\prime}, 5$ $\mathrm{HxCB}(\# 156)$ and $2,3,3^{\prime}, 4,4^{\prime}, 5^{\prime}-\mathrm{HxCB}(\# 157)$. The physiochemical properties of $2,3,4,4^{\prime}, 5-\mathrm{PeCB}(\# 114)$ is more similar to those of $2,3^{\prime}, 4,4^{\prime}, 5-\mathrm{PeCB}(\# 118)$ than those of 2,3,3',4,4',5-HxCB(\#156) and 2,3,3',4,4',5' -HxCB(\#157) (Eguchi et al. 2015), so different exposure sources could explain why $2,3,4,4$ ',5-PeCB(\#114) did not cluster with the

Table 4 Spearman's rank correlation and nonparametric bootstrap confidence intervals between the sum of 3,3',4,4'-TeCB(\#77) and the representative dioxin-like $\mathrm{PCBs}$ and total $\mathrm{PCDD} / \mathrm{F}$

\begin{tabular}{lll}
\hline & Spearman's $\rho$ & $95 \%$ CI \\
\hline Maternal blood & 0.74 & $0.53-0.86$ \\
Cord blood & 0.73 & $0.46-0.86$ \\
Cord tissue & 0.68 & $0.39-0.82$ \\
Cord tissue $^{\mathrm{a}}$ & 0.73 & $0.46-0.85$ \\
\hline
\end{tabular}

${ }^{\mathrm{a}}$ With additional higher chlorinated dioxin-like PCBs 
other PentaCBs. Alcock et al. (1998) report that Aroclor formulations have dominated exposure to the lower chlorinated PCBs, especially 3,3',4,4'-TeCB(\#77), while combustion processes were found to be the source of higher chlorinated PCBs. It is possible that exposure to $2,3,4,4^{\prime}, 5-\mathrm{PeCB}(\# 114)$ follows similar routes as exposure to higher chlorinated PCBs; although, we have found no literature sources confirming this. A similar pattern was found in 41 Yucheng victims (Hsu et al. 2005) in which 2,3,4,4',5-PeCB(\#114), 2,3,3',4,4',5-HxCB(\#156), and 2,3,3',4,4', ,' '-HxCB(\#157) were found to co-vary. Although $2,3^{\prime}, 4,4^{\prime}, 5-\mathrm{PeCB}(\# 118$ ) was measured, the number of nondetectable values was high for that congener and it was not included in the principal component analysis. Hsu et al. (2005) also studied PCDD/Fs and found similar principal component loadings for 1,2,3,4,7,8-HxCDF and 1,2,3,6,7,8-HxCDF which also clustered together in our data.

The population from which the individuals in the present study is sampled is a very homogeneous one, and the fact that similar clustering patters are observed in different populations of different ages add strength to our findings. The sum of the representative PCBs and total PCDD/F correlated well in all three matrices; although, the correlation was slightly lower in cord blood and cord tissue than in maternal blood (see Table 4). Levels of total dioxinlike PCB and PCDD/F decreased in cord blood compared to maternal blood but rose again in cord tissue (see Table 2) which fits well with previous results regarding levels and correlations of $\mathrm{PCBs}$ and $\mathrm{PCDD} / \mathrm{Fs}$ in the three matrices (Fukata et al. 2005; Grandjean et al. 2001; Waliszewski et al. 2000; Walker et al. 2003; Sala et al. 2001).

Based on the results in this study, the sum of 3,3',4,4'-TeCB(\#77), 2,3',4,4',5-PeCB(\#118), 3,3',4,4',5PeCB(\#126), 2,3,3',4,4',5,5'-HpCB(\#189), and 2,3,4,4',5$\mathrm{PeCB}(\# 114)$ could well be used as a proxy for fetal exposure to total dioxin-like PCB and PCDD/F in studies taking a whole mixtures approach. For measurements made in cord tissue, we suggest that additional higher chlorinated dioxin-like PCBs should be measured and included in the sum.

Two major limitations of this study are the low sample size and the large number of PCDD/Fs below the LOD. It is therefore important that these results are replicated in larger studies in different populations. The population studied cannot be considered highly exposed to PCBs and PCDD/Fs when compared to those exposed by, e.g., the Seveso incident or Agent Orange in Vietnam. However, Alcock et al. (1998) reported that the contribution of dioxinlike PCBs to total TEQ was comparable to that of PCDD/Fs in normal populations and in human milk fat and is usually dominated by PCB 156 (23-36\%), PCB 126 (22-37\%), and PCB 118 (10-17\%), which collectively constitute between 50 and $90 \%$ of the $\Sigma$ PCB-TEQ.
The number of measurements below the LOD was high for some $\mathrm{PCDD} / \mathrm{Fs}$, and those were not included in the final analysis. Values below the LOD were imputed by LOD/2 resulting in observations below the LOD being given the same value. The rank-based measure splits tied values randomly when assigning ranks and could thus dilute any relationship. This can also have contributed to the lack of stable clusters among the PCDD/Fs. This study focused on dioxin-like PCBs, and data for nondioxin-like PCBs was not available. It would be valuable to repeat these analyses in data where both dioxin-like and nondioxin-like PCBs were measured to assess if any nondioxin-like PCBs could be used as fetal exposure markers.

In conclusion, there was relatively little co-variation between the studied contaminants suggesting that to get a complete picture of fetal exposure, several contaminants need to be measured. Five dioxin-like PCBs can be used as representative PCBs for total fetal dioxin-like PCB exposure. Our results also suggest that the sum of the representative dioxin-like PCBs and 3,3',4,4'-TeCB(\#77) can be used as a proxy for total PCDD/F exposure in this population and in populations with similar exposure profiles, but the correlation is lowest in cord tissue, where it may be necessary to measure an additional number of higher chlorinated dioxin-like PCBs to get a good proxy measure.

Open Access This article is distributed under the terms of the Creative Commons Attribution 4.0 International License (http:// creativecommons.org/licenses/by/4.0/), which permits unrestricted use, distribution, and reproduction in any medium, provided you give appropriate credit to the original author(s) and the source, provide a link to the Creative Commons license, and indicate if changes were made.

\section{References}

Alcock R, Behnisch P, Jones K, Hagenmaier H (1998) Dioxin-like PCBs in the environment-human exposure and the significance of sources. Chemosphere 37(8):1457-1472

Crain D, Janssen S, Edwards T, Heindel J, Ho S, Hunt P, Iguchi T, Juul A, McLachlan J, Schwartz J, Skakkebaek N, Soto A, Swan S, Walker C, Woodruff T, Woodruff T, Giudice L, Guillette Jr L (2008) Female reproductive disorders: the roles of endocrine-disrupting compounds and developmental timing. Fertil Steril 90:911-40

Eguchi A, Hanazato M, Suzuki N, Matsuno Y, Todaka E, Mori C (2015) Maternal-fetal transfer rates of PCBs, OCPs, PBDEs, and dioxin-like compounds predicted through quantitative structureactivity relationship modeling. Environ Sci Pollut Res. https://doi. org/10.1007/s11356-015-5436-0

Fukata H, Omori M, Osada H, Todaka E, Mori C (2005) Necessity to measure $\mathrm{PCBs}$ and organochlorine pesticide concentrations in human umbilical cords for fetal exposure assessment. Environ Health Persp 113:297-303

Govarts E, Nieuwenhuijsen M, Schoeters G, Ballester F, Bloeman K, de Boer M, Chevrier C, Eggesbø M, Guxens M, Krämer U, Legler J, Martínez D, Palkovicova L, Patelarou E, Ranft U, Rautio A, Petersen M, Slama R, Stigum H, Toft G, Trnovec T, Vandentorren S, Weihe P, Kuperus N, Wilhelm M, Wittsiepe J, Bonde J, OBELIX, ENRIECO (2012) Birth weight 
and prenatal exposure to polychlorinated biphenyls (PCBs) and dichlorodiphenyldichloroethylene (DDE): a meta-analysis within 12 european birth cohorts. Environ Health Perspect 120:162-70

Grandjean P, Landrigan P (2006) Developmental neurotoxicity of industrial chemicals. Lancet 368:2167-2178

Grandjean P, Weihe P, Burse V, Needham L, Storr-Hansen E, Heinzow B, Debes F, Murata K, Simonsen H, Ellefsen P, Budtz-Jørgensen E, Kieding N, White R (2001) Neurobehavioral deficits associated with pcb in 7-year-old children prenatally exposed to seafood neurotoxicants. Neurotoxicol Teratol 23:305-17

Grimm FA, Hu D, Kania-Korwel I, Lehmler HJ, Ludewig G, Hornbuckle KC, Duffel MW, Bergman Å, Robertson LW (2015) Metabolism and metabolites of polychlorinated biphenyls. Crit Rev Toxicol 45(3):245-272

Harrell FE Jr (2001) Regression modeling strategies. With applications to linear models, logistic regression and survival analysis. Springer, New York

Harrell FE Jr (2014) Hmisc: Harrell miscellaneous. http://CRAN. $\mathrm{R}$-project.org/package=Hmisc, R package version 3.14-4

Hsu JF, Guo YL, Yang SY, Liao PC (2005) Congener profiles of PCBs and $\mathrm{PCDD} / \mathrm{Fs}$ in Yucheng victims fifteen years after exposure to toxic rice-bran oils and their implications for epidemiologic studies. Chemosphere 61(9):1231-1243

Kawashiro Y, Fukata H, Omori-Inoue M, Kubonoya K, Jotaki T, Takigami H, Sakai S, Mori C (2008) Perinatal exposure to bromina ted flame retardants and polychlorinated biphenyls in Japan. Endocr J 55(6):1071-1084. https://doi.org/10.1507/endocrj.K08E-155

Kogevinas M (2001) Human health effects of dioxins: cancer, reproductive and endocrine system effects. Hum Reprod Update 7:331-9

Lampa E, Lind L, Bornefalk-Hermansson A, Salihovic S, van Bavel B, Lind PM (2012) An investigation of the co-variation in circulating levels of a large number of environmental contaminants. J Expo Sci Env Epid 22:476-482

Lancz K, Murínová L, Patayová H, Drobná B, Wimmerová S, Šovičíková E, Kováč J, Farakašová D, Herz-Piciotto I, Jusko TA, Trnovec T (2014) Ratio of cord to maternal serum PCB concentrations in relation to their congener-specific physiochemical properties. Int J Hyg Envir Heal 218:91-98

Mori C, Nakamura N, Todaka E, Fujisaki T, Matsuno Y, Nakaoka H, Hanazato M (2014) Correlation between human maternalfetal placental transfer and molecular weight of PCB and dioxin congeners/isomers. Chemosphere 114:262-267
Oakley G, Devanaboyina U, Robertson L, Gupta R (1996) Oxidative DNA damage induced by activation of polychlorinated biphenyls (PCBs): implications for PCB-induced oxidative stress in breast cancer. Chem Res Toxicol 9:1285-92

R Core Team (2014) R: a language and environment for statistical computing $r$ foundation for statistical computing. Vienna, Austria. http://www.R-project.org/

Sakurai K, Todaka E, Saito Y, Mori C (2004) Pilot study to reduce dioxins in the human body. Intern Med 43:792-795

Sala M, Ribas-Fitó N, Cardo E, de Muga M, Marco E, Mazón C, Verdú A, Grimalt J, Sunyer J (2001) Levels of hexachlorobenzene and other organochlorine compounds in cord blood: exposure across placenta. Chemosphere 43:895-901

Shimodiara H (2005) Approximately unbiased tests of regions using multistep-multiscale bootstrap resampling. Ann Stat 32:26162641

Suzuki R, Shimodaira H (2011) Pvclust: hierarchical clustering with p-values via multiscale bootstrap resampling. http://CRAN. $\mathrm{R}$-project.org/package=pvclust, $\mathrm{R}$ package version $1.2-2$

Svensson B, Hallberg T, Nilsson A, Schütz A, Hagmar L (1994) Parameters of immunological competence in subjects with high consumption of fish contaminated with persistent organochlorine compounds. Int Arch Occup Environ Health 65:351-8

Tsukimori K, Morokuma S, Hordi T, Takahashi K, Hirata T, Otera Y, Fukushima K, Kawamoto T, Wake N (2013) Characterization of placental transfer of polychlorinated dibenzo-p-dioxins, dibenzofurans and polychlorinated biphenyls in normal pregnancy. $\mathbf{J}$ Obstet Gynaecol Res 39:83-90

Van den Berg M, Birnbaum LS, Denison M, De Vito M, Farland W, Feeley M, Fiedler H, Håkansson H, Hanberg A, Haws L, Rose M, Safe S, Schrenk D, Tohyama C, Tritscher A, Tuomisto J, Tysklind M, Walker N, Peterson RE (2006) The 2005 World Health Organization reevaluation of human and mammalian toxic equivalency factors for dioxins and dioxin-like compounds. Toxicol Sci 93(2):223-241

Waliszewski S, Aguirre A, Infanzón R, Siliceo J (2000) Carry-over of persistent organochlorine pesticides through placenta to fetus. Salud Publica Mex 42:384-90

Walker J, Seddon L, McMullen E, Houseman J, Tofflemire K, Corriveau A, Weber J, C M SmithS, van Oostdam J (2003) Organochlorine levels in maternal and umbilical cord blood plasma in Arctic Canada. Sci Total Environ 302:27-52 